\title{
On the Use of Ballast Inspection Technology For the Management of Track Substructure
}

\author{
Allan M. Zarembski • Gregory T. Grissom • \\ Todd L. Euston
}

Accepted: 23 January 2014 / Published online: 15 February 2014

C) Springer New York 2014

\begin{abstract}
The railroad track substructure and specifically its ballast and sub-ballast layers play a key role in the maintenance of the stability and geometry of the track structure. However, because it traditionally has not been readily accessible below the surface of the ballast, very limited information about its conditions was available, without extensive and disruptive excavation techniques. New-generation inspection technology now allows for the access to significant additional information about the ballast and sub-ballast to include its extent, condition, depth, degree of fouling, and any inadequacies in the substructure layer that can lead to loss of track stability or accelerated degradation of the track structure. This paper discusses several of the key track substructure inspection technologies, to include the traditional monitoring of the track geometry and then addresses the new inspection technologies now available to more accurately define the ballast condition. This includes such newly introduced inspection technologies as LIDAR for measurement of the ballast profile, ground penetrating radar inspection for ballast depth deficiency, and other related inspection technologies. These new technologies allow for more accurate ballast deficit and condition analysis.
\end{abstract}

Keywords Ballast · Track substructure - Inspection · Maintenance

\section{Introduction to the Track Substructure}

The railroad track substructure and specifically its ballast and sub-ballast layers play a key role in the maintenance of the stability and geometry of the track structure.

\footnotetext{
A. M. Zarembski $(\bowtie)$

Railroad Engineering and Safety Program, University of Delaware, Newark, DE 19716, USA

e-mail: dramz@udel.edu

G. T. Grissom • T. L. Euston

Georgetown Rail Equipment Company, Georgetown, TX, USA
} 
Ballast refers to the upper stratum or layer of the track substructure upon which the superstructure (i.e., the rails and ties) is placed (Fig. 1). It generally represents a permeable granular material(s) placed around and under the ties to promote track stability.

Subgrade refers to the material under the ballast and sub-ballast layers which could be the original or parent material of the site, or a "fill" material added during the construction process.

The ballast section is the layer of the track structure that is located between the ties and the subgrade, as illustrated in Fig. 1. The principal parts of the ballast section are:

1. Ballast cribs. The ballast located between ties, above the bottom of the tie.

2. Ballast shoulders. The ballast located outside the ends of the ties; usually configured with a flat portion, at a height equal to the top of tie and a sloping portion that continues until it reaches the sub-ballast or subgrade layer.

3. Ballast layer beneath the bottom of the tie. This layer extends to the subgrade and can include the sub-ballast layer.

The ballast section is a key part of the track structure. It serves several essential functions including distribution of vertical load from the bottom of the tie to the top of the subgrade, providing lateral and longitudinal restraint for the tie and track superstructure (rail, ties, and fasteners), allowing for correction of track geometry variations, facilitating drainage, providing damping for noise, vibration, and dynamic impact loads, etc.

An adequate ballast section beneath the tie will reduce the level of vertical dynamic loading from the bottom of the tie to the top of the subgrade, thus reducing the vertical degradation of the track structure and its geometry (surface or profile, cross-level, twist, warp, etc.). It will also serve to provide dynamic attenuation and damping of the wheel/ rail loads, to include impact loading such as from wheel flats, engine burns or other discontinuities at the wheel/rail interface. Likewise, proper and adequate ballast shoulders and cribs provide lateral and longitudinal resistance to movement of the track superstructure, reducing the lateral degradation of the track geometry (alignment).

An inadequate ballast section will result in high rates of track geometry degradation in the vertical and/or lateral directions, necessitating frequent track maintenance [10]. It can also result in more catastrophic types of failures, such as a track buckle, which can end in a derailment of a passing train $[12,14]$.

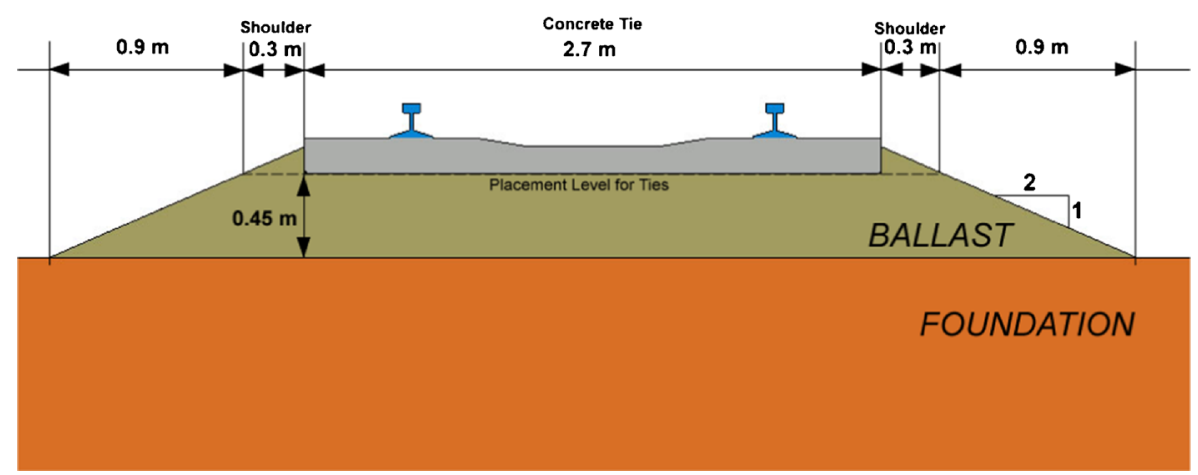

Fig. 1 Ballast section (example) 
Thus, maintenance of an adequate ballast section, to include shoulders, cribs, and ballast layer under the tie, is of real importance from both a maintenance and safety point of view. Degradation manifests itself as changes in track geometry usually over time to include:

- Vertical (degradation of track geometry in the vertical plane to include Surface, Cross-level, Twist)

- Lateral (degradation of track geometry in the lateral plane to include Alignment)

For example, an adequate ballast section beneath the tie will reduce the level of vertical dynamic loading from approximately 448 to $586 \mathrm{MPa}$ (65 to $85 \mathrm{psi}$ ) at the bottom of the tie to approximately 138 to $172 \mathrm{MPa}$ (20 to $25 \mathrm{psi}$ ) at the top of the subgrade [14]. It will thus allow for the reduction of the significant level of loading to a level that even a "weak" subgrade can support. Correspondingly, an inadequate depth of ballast can result in "overstressing" of the subgrade, particularly a weak or wet subgrade, with a corresponding increase in the rate of track surface degradation (e.g., surface/profile, cross-level, etc.).

Likewise, adequate shoulders will provide lateral restraint to the cross-ties and the track superstructure itself, resisting both short- and long-term lateral movement of the track, and facilitating maintenance of the track alignment. This is particularly true for continuously welded rail (CWR) track, where inadequate ballast shoulders, and the associated inadequate lateral track resistance, can result in rapid loss of alignment or even buckling of the track structure [6]. Studies have shown that inadequate shoulders can result in a loss of overall track resistance on the order of 20 to $40 \%[3,7]$.

Similarly, full cribs will provide longitudinal resistance to the movement of the ties, to prevent tie skewing or movement along the track. Tests have shown that half-empty cribs can reduce tie longitudinal restraint by the order of $50 \%$ or more [9].

Thus, maintenance of an adequate ballast section, to include shoulders, cribs and ballast layer under the tie, is of real importance from both a maintenance and safety point of view $[5,10]$.

\section{Track and Ballast Inspection Technologies}

Traditionally, ballast section is inspected as part of the regular weekly or bi-weekly walking (or slow speed) track inspection activity where the inspector will note any locations with inadequate ballast sections. As such, it is a subjective inspection process, where the inspector visually evaluates the condition of the ballast and any locations where the ballast section is inadequate. This subjective process usually results in the reporting of locations with significant deficiencies (e.g., missing or small shoulders, open cribs, etc.), but locations with less than obvious deficiencies are often overlooked. Thus, while locations where standing water or "pumping" of mud or other contaminants are visible, they can be readily detected by the inspector. However, where they do not make it to the surface, they are generally "invisible" to the inspector.

In the last several decades, track geometry inspection, the measurement of the "geometry" of the track at its surface, i.e., at the top of the rail head, has been used to supplement and complement the walking track inspector and to provide quantitative information about the track. Since the majority of track geometry parameters are directly 
related to the ballast and subgrade, track geometry inspection has become a surrogate for ballast condition inspection. This is particularly true when the rate of geometry degradation is analyzed. This is because traditionally, ballast condition information has not been readily accessible below the surface of the ballast, with very limited information about conditions available without extensive and disruptive excavation.

However, new-generation inspection technologies now allow for the access to significant additional information about the ballast and sub-ballast to include its extent, condition, depth, degree of fouling, and any inadequacies in the substructure layer that can lead to loss of track stability or accelerated degradation of the track structure. These includes such newly introduced inspection technologies as LIDAR for measurement of the ballast profile, ground penetrating radar inspection for ballast depth deficiency, and other related inspection technologies such as cone penetrometer and track modulus measurement.

\section{Track Geometry Car}

Use of track geometry inspection vehicles, generally referred to as track geometry cars or track recording cars, have become part of the "normal" inspection of the track and in particular the track geometry. These inspection vehicles measure the key track geometry parameters of;

- Gage

- Curvature

- Cross-level

- Track cant (super elevation)

- Alignment

- Surface (or profile)

- Twist/warp

Track geometry cars can be either rail-bound (either self-propelled or locomotive hauled) or hy-rail vehicle based with both rail and over-the-road capability.

The use of track recording cars (track geometry cars) has been active in the railroad industry for many decades and has proven to be invaluable in reduction of track geometry related defects as well as for improved track maintenance

Modern track geometry measurement systems make use of inertial sensors to locate a measurement reference frame relative to the track and laser scanning systems to locate the rails relative to the measurement reference frame.

The resulting measurements are recorded both in analog (strip chart) (Fig. 2a) and digital format (Fig. 2b) to allow for exception reporting as well as more sophisticated analysis of the geometry data. That allows for an understanding of deteriorated or failed ballast and/or subgrade conditions. This will be discussed further, later in this paper.

\section{LIDAR}

LIDAR represents a new inspection technology being applied in the railroad industry to measure and map the ballast profile [14]. LIDAR which stands for LIght Detection 
a

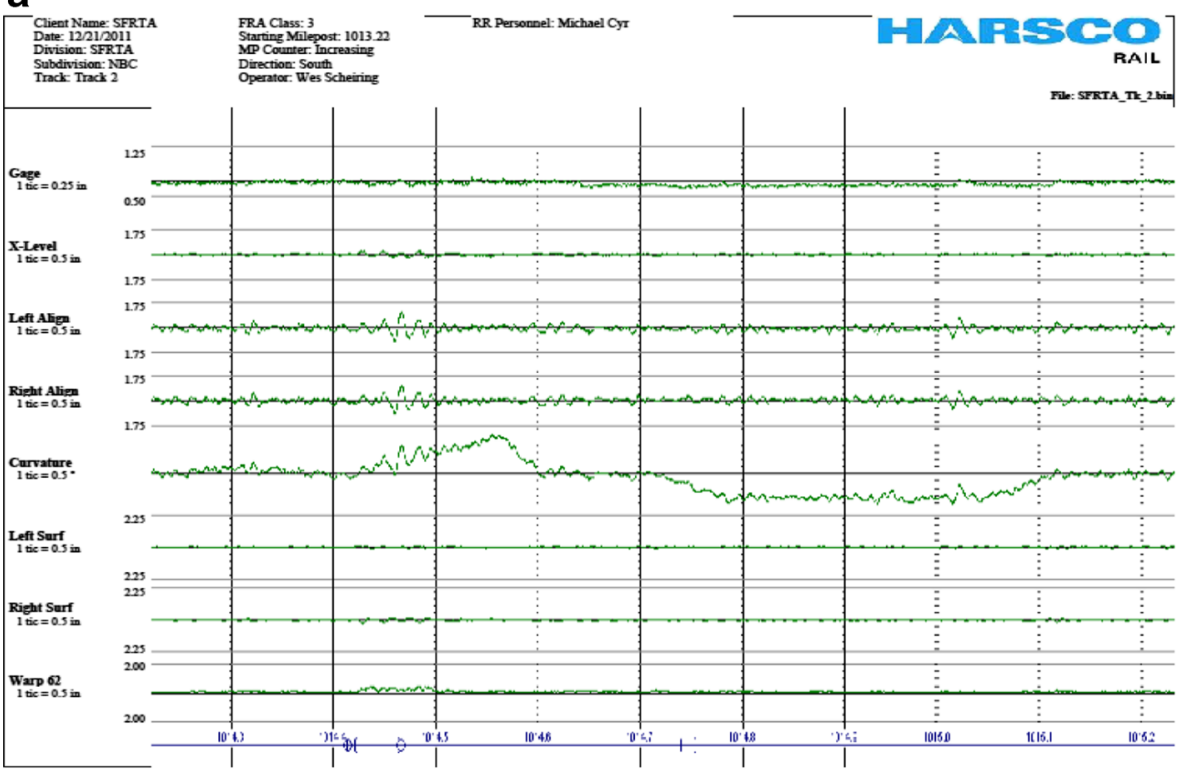

b

\begin{tabular}{|c|c|c|c|c|c|c|c|c|c|c|}
\hline \multirow[b]{2}{*}{ №. } & \multicolumn{10}{|c|}{$\begin{array}{c}\text { Track Geometry Inspection - Exception Report for: Railroad } \\
\text { Division: Div A Subdivision: Sub } 1 \\
\text { Track: Main } \\
\text { 5/16/2012 File Name: Main3_006.bin } \\
\text { Minimum Exception Length: } 3 \text { Feet Units of Measure: English }\end{array}$} \\
\hline & $\underline{\text { Start MP }}$ & Track & Length & Parameter & Max & Benchmark & $\underline{\text { Offset }}$ & Un Gage & Class & Safe \\
\hline 1 & 0.043 & Main & 4 & Y.Lt. Ali Tan: 3.00 & 3.61 & None:Stop & .20 & 0.28 & 1 & - \\
\hline 2 & 0.044 & Main & 3 & Y-Rt. Ali Tan 3.00 & 3.33 & None:Stop & -20 & 0.28 & $i$ & - \\
\hline 3 & 0.044 & Main & 11 & Y-Rt. Ali Cu: 3.00 & 3.63 & Ldmk:FRPT 17 & -12 & 0.15 & $i$ & $\overline{-}$ \\
\hline 4 & 0.044 & Main & 11 & Y-Lt Ali Cu: $3.0 \mathrm{C}$ & 3.77 & Ldmk:FRPT 17 & -12 & 0.15 & $i$ & $=$ \\
\hline 5 & 0.048 & Main & 6 & R-Gage Tight: 0.50 & -0.72 & Ldmk:FRPT 17 & 2 & -0.72 & 1 & $\overline{\mathrm{E}}$ \\
\hline 6 & 0.053 & Main & 11 & Y-Lt. Ali Tan: 3.00 & -4.95 & Ldmk:FRPT 17 & 37 & -0.07 & 1 & - \\
\hline 7 & 0.053 & Main & 12 & Y-Rt. Ali Tan 3.00 & -4.99 & Ldmk:FRPT 17 & 38 & $\begin{array}{l}-0.07 \\
-0.07\end{array}$ & 1 & $\begin{array}{c}- \\
-\end{array}$ \\
\hline 8 & 0.055 & Main & 9 & R-Lt. Ali Tan: 5.00 & -5.33 & Ldmk:FRPT 17 & 46 & 0.09 & 1 & $\overline{\mathrm{E}}$ \\
\hline $9_{9}^{\circ}$ & 0.056 & Main & 10 & R-Rt. Ali Tan: 5.00 & -5.41 & Ldmk:SWPT 17 & $\begin{array}{l}40 \\
-19\end{array}$ & 0.09 & 1 & $\mathrm{E}$ \\
\hline 10 & 0.057 & Main & 12 & Y-Lt Ali Tan: 3.00 & -4.96 & Ldmk:FRPT 1718 & -13 & 0.22 & 1 & 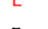 \\
\hline 11 & 0.058 & Main & 9 & Y-Rt. Ali Tan: 3.00 & -4.84 & Ldmk:FRPT 1718 & -11 & 0.04 & $i$ & $=$ \\
\hline 12 & 0.069 & Main & 18 & Y-Rt. Ali Cu: 3.00 & 3.49 & Ldmk:SWPT 1718 & -19 & -0.01 & $i$ & - \\
\hline 13 & 0.070 & Main & 16 & Y-Lt. Ali Cu: 3.00 & 3.48 & Ldmk:SWPT 1718 & -18 & -0.01 & 1 & \\
\hline 14 & 0.081 & Main & 4 & R-Gage Tight: 0.50 & -0.64 & Ldmk:FRPT 1516 & 6 & -0.64 & 1 & $\overline{\mathrm{E}}$ \\
\hline
\end{tabular}

Fig. 2 a Geometry car strip chart report. b Track geometry exception report

And Ranging, or Laser Imaging Detection And Ranging uses optical remote sensing technology that can measure the distance to, or other properties of, targets by illuminating the target with laser light and analyzing the backscattered light. LIDAR technology has specifically been applied in the railroad industry in measuring and mapping the surface of the track, and in particular, the ballast profile of the track structure.

These have been used in commercial applications such as the LIDAR-based BallastSaver track inspection system ${ }^{1}$ designed to scan the track at up to $48 \mathrm{kph}$

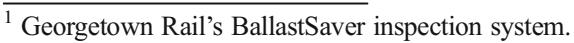


Fig. 3 GREX ballast saver ballast profile inspection vehicle

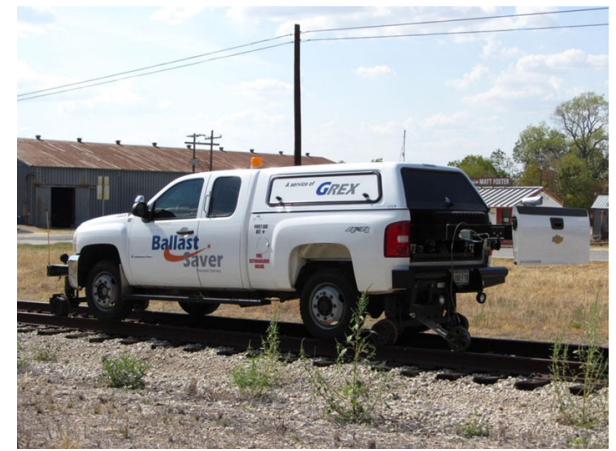

(30 mph) and calculate ballast deficiencies in cubic feet along any desired length of contiguous track. A photograph of this inspection vehicle is shown in Fig. 3.

The BallastSaver system is operated by the hy-rail truck driver, who operates the LIDAR inspection system and marks key track locations. A LIDAR unit is a combined laser source and detector that rotates continuously to determine the distance to the nearest solid object by detecting its laser light reflection. To measure the track surface profile, each of the two LIDAR units rotates and measures the reflection of the laser to determine the distance from the laser source/detector, which produces two sets of data which are converted to Cartesian coordinates. As the measurement truck travels along the track, the collection and storage of the LIDAR data is continuous, and so aggregating a series of consecutive cross-sections produces a three-dimensional track profile surface.

At the conclusion of the scan, the BallastSaver analysis is performed where the appropriate tangent or curve ideal track profile is overlaid with the measured data to calculate the ballast deficiency volume along the track (Fig. 4).

The result of this LIDAR ballast profile analysis is a report that defines missing ballast (to include shoulder and crib ballast) per length of track. This report is presented in both tabular and graphical form (Fig. 5). This is also defined in terms of how many total cars of ballast are required per mile together with the exact start and stop locations, which is also used to generate an output file that serves as an automated input file for an automated ballast delivery system.

This LIDAR inspection system can be utilized as a stand-alone tool, as part of a ballast delivery planning program or alternatively as a means to collect the necessary information to automate the ballast delivery using state of the art ballast delivery trains.

\section{Ground Penetrating Radar}

Inspection of the ballast and sub-ballast layer and associated measurement of the depth of the ballast layer are being performed using Ground penetrating radar (GPR) which allows for the mapping of the ballast section beneath the cross-tie, and the specific measurement of the condition of and depth of ballast to the top of the subgrade. GPR is a nondestructive inspection method that uses electromagnetic radiation in the microwave band (UHF/VHF frequencies) of the radio spectrum, and detects the reflected 


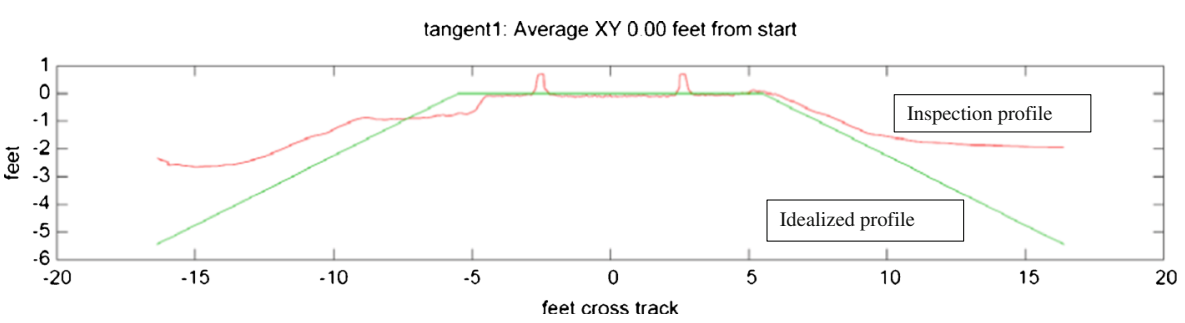

Fig. 4 LIDAR inspection profile overlay on idealized railroad profile

signals from subsurface structures. GPR can be used in a variety of media, including rock and soil. GPR uses high-frequency (usually polarized) radio waves and transmits into the ground. When the wave hits a boundary with different dielectric constants, the receiving antenna records variations in the reflected return signal. In the railroad application, good penetration is achieved in ballast materials such as granite and limestone. The change in material from ballast to soil represents a detectable boundary layer, as are locations where moisture is present. Clay-laden soils and soils with high electrical conductivity are also readily detectable.

GPR systems have been mounted on hy-rail vehicles such as shown in Fig. 6 to image the subsurface of the track and to map the ballast and top of the subgrade sections of the track structure. The unit shown in Fig. 6 has three GPR units positioned to measure the center and outside sections of the ballast.

Until recently, GPR has been difficult to use; however, advances in analysis technology to analyze the GPR signal and convert the reflected images to condition data, to include degree of fouling or contamination, have made GPR data more userfriendly and useful. Such an analysis is shown in Fig. 7 which presents (in color-coded format) the results of the analysis of the GRP data. Thus, each of the horizontal bars

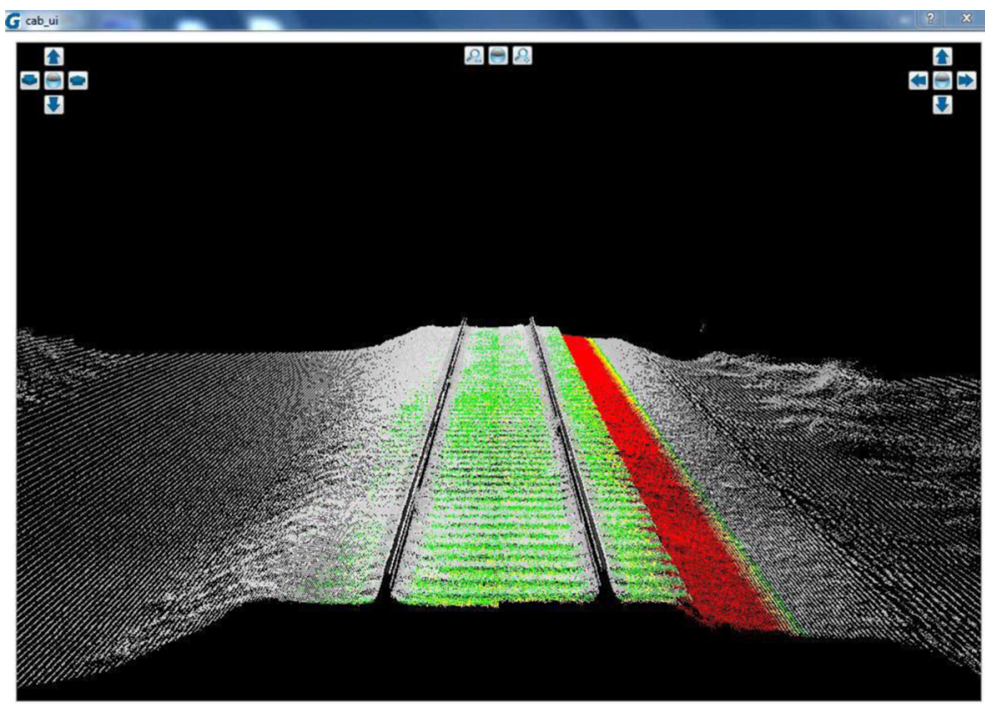

Fig. 5 LIDAR ballast profile image: deficient ballast zones in red 
Fig. 6 Photo of hy-rail mounted GPR unit

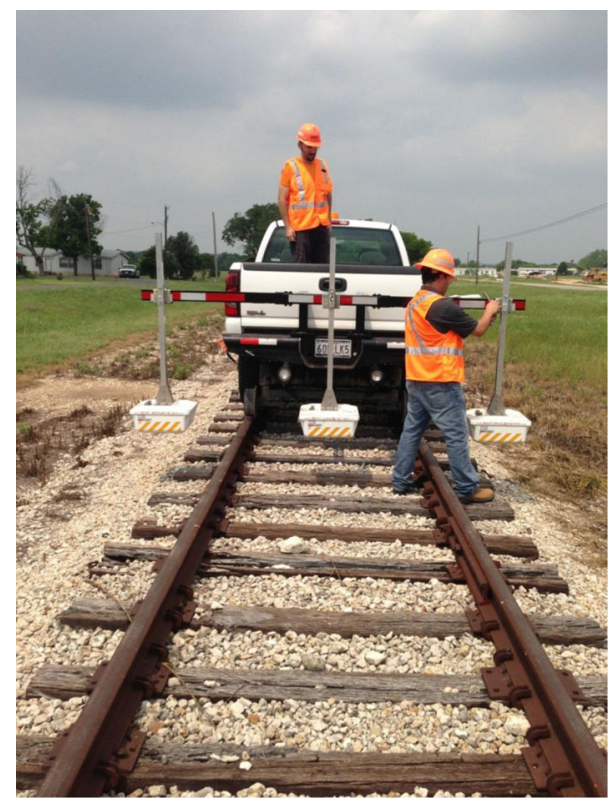

shown on the bottom of Fig. 7, represents a color-coded value for the relevant parameters to include:

- Degree of ballast fouling (color-coded as follows)

$-0=$ green $=$ clean

$-1=$ yellow $=$ mostly clean

$-2=$ orange $=$ slightly fouled

$-3=$ red $=$ fouled

- Ballast moisture content (within ballast and also moisture at the base of ballast)

- Defined as a continuous numeric (and color) scale from 1-255 where

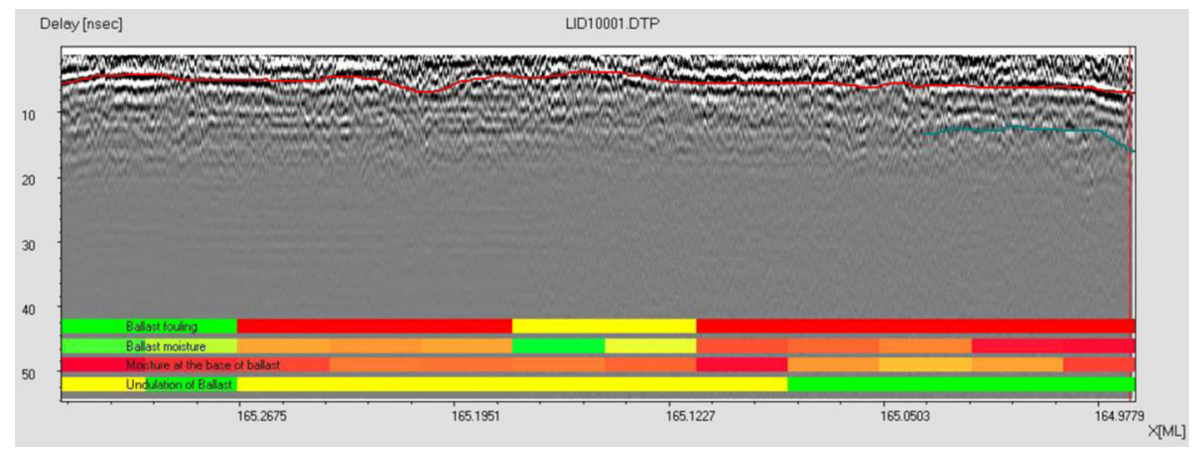

Fig. 7 GPR output showing ballast condition (color-coded on bottom) 


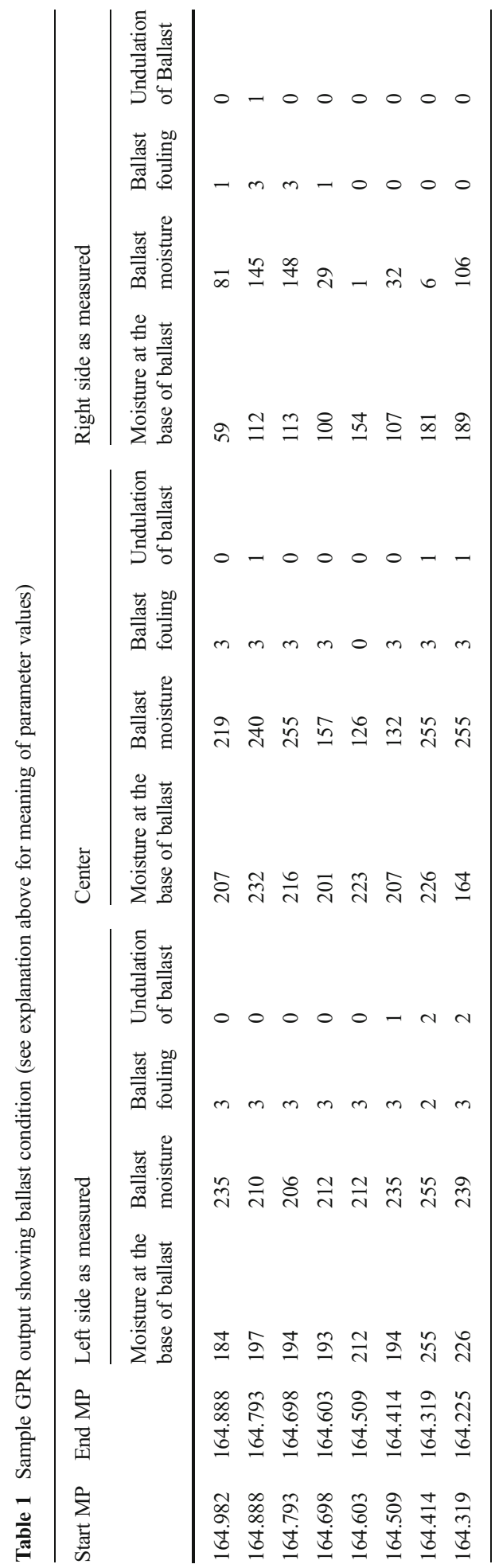




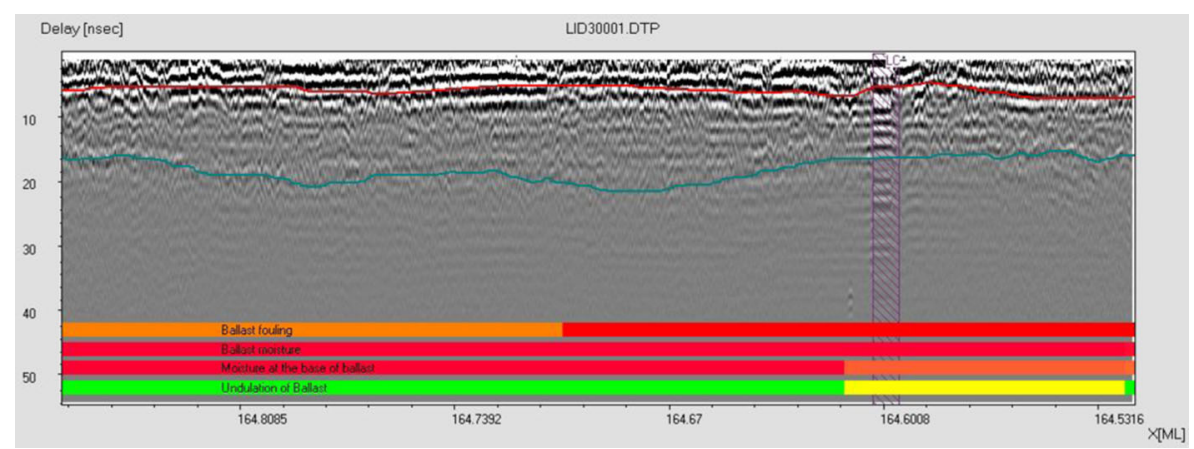

Fig. 8 GPR data showing bottom of ballast layer (red) and top of subgrade (blue)

$$
\begin{aligned}
& 1=\text { green }=\text { dry } \\
& 255=\text { red }=\text { wet }
\end{aligned}
$$

- Undulation of ballast layer (color-coded as follows)

$-\quad 0=$ green $=$ mostly even

$-\quad 1=$ yellow $=$ slightly undulated

$-\quad 2=\mathrm{red}=$ undulated $/$ settled

Table 1 presents a sample analysis of ballast condition from a GPR field test.

The GPR data has also been used to determine depth of ballast and location of top of subgrade as illustrated in Fig. 8 and Table 2 which shows a GPR test where the depth of ballast is clearly defined.

\section{Cone Penetrometer}

Cone penetrometer is a standard soil test procedure that has been adapted for use in inspection of ballast and subgrade conditions. Cone penetration test (CPT) is used to directly measure stiffness, strength and thickness of the substructure layers. The test is performed using a standardized cone-shaped probe with a force measuring tip which is pushed continuously from the ballast surface down into the subgrade. The probe is usually pushed at least 15 to $25 \mathrm{ft}$ below the surface to capture the depth of influence of the substructure on the track deflection. The measurements represent the resistance provided by the ballast and sub-ballast as illustrated in Fig. 9.

Railway applications of the CPT include:

- Determination of the strength of the ballast, sub-ballast and subgrade zones

- Determination of the depth of the ballast, sub-ballast zones

- Determination of any variation in strength properties across these zones

- Analyzing the adequacy of the ballast/sub-ballast thickness to prevent subgrade failure

- Evaluating the effectiveness of subgrade improvement techniques such as lime slurry pressure injection 


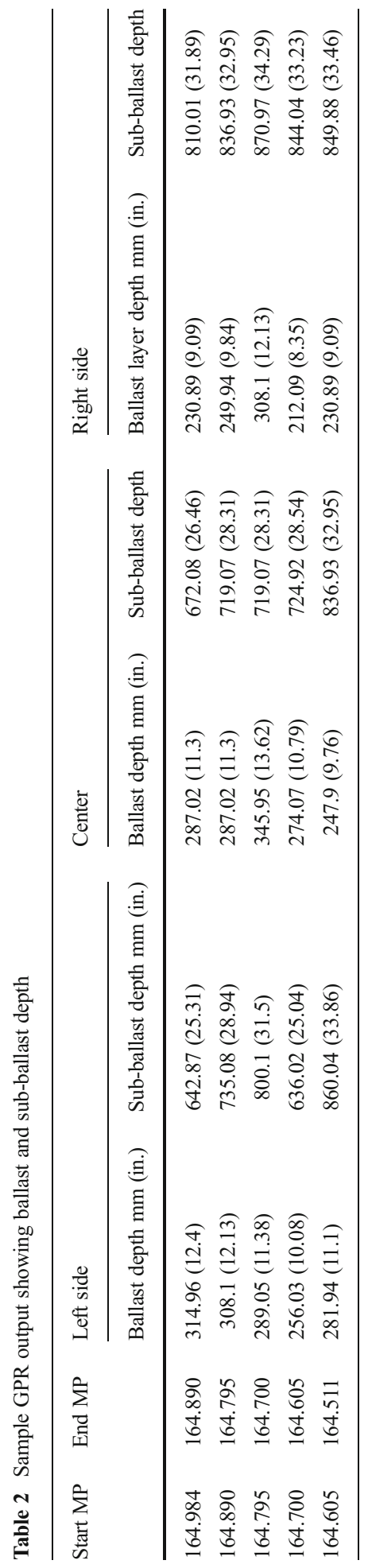




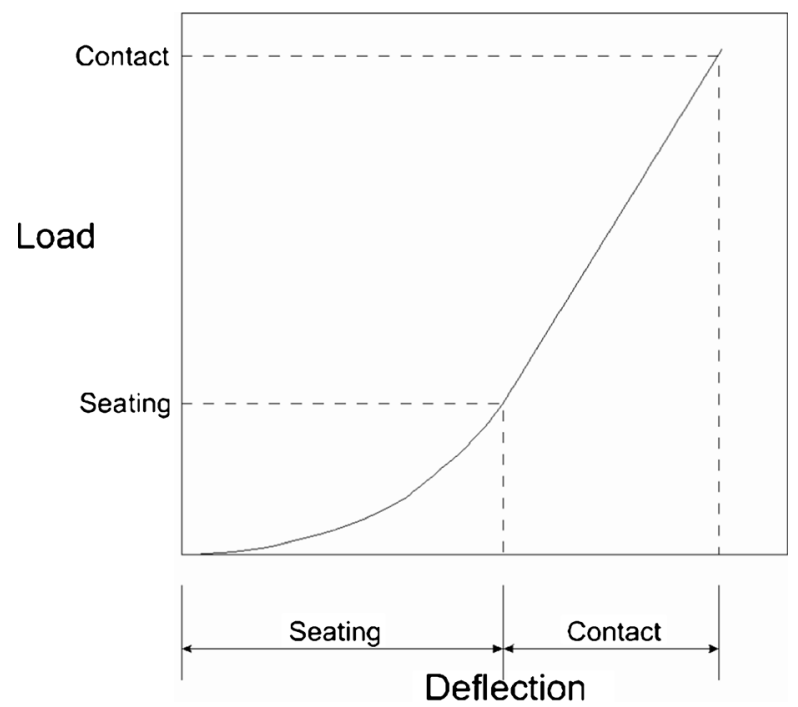

Fig. 9 Track load-deflection curve for determination of track modulus

\section{Track Modulus}

Track modulus is a traditional measure of the "stiffness" or deflection under load of the track structure as a whole, to include the ties (sleepers), ballast and subgrade. As such, track deflection or stiffness is used as a measure of the vertical condition of the track.

Traditional track modulus testing has been stationary, measuring first deflection without load, and then increasing load to get a load-deflection curve at a given point in track (Fig. 10) [13].

Field techniques exist for measurement of track modulus

- Under passing vehicle (slow speed) [11]

- Under stationary vehicle [5, 13]

- Under test car [8]

As seen in Fig. 9, track load-deflection curves are generally nonlinear. The initial portion of the curve, which includes any "slack" in the system, such as voids under ties, clearly shows this nonlinear behavior. By analyzing the shape of this load-deflection curve, an indication of the condition of the ballast can be obtained. Thus, for example, the slope of the upper part of the curve can be an indication of the stiffness of the subsurface layers.

Traditionally inspection systems provide condition information regarding the ballast on a "go/no-go" or "pass/fail" basis. However, new-generation analysis tools and

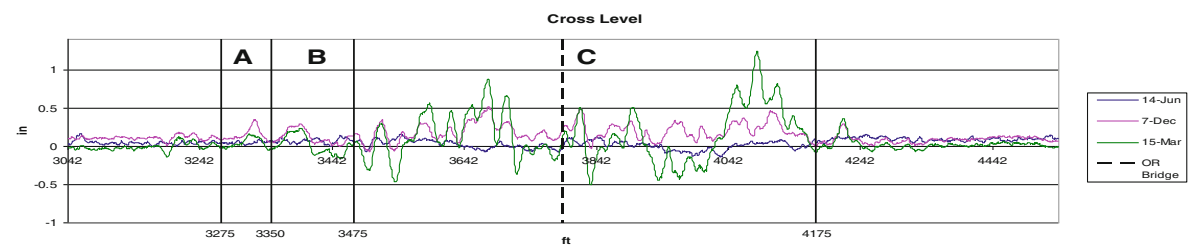

Fig. 10 Track geometry degradation with time for $300 \mathrm{~m}(1,000 \mathrm{ft})$ of track 
Table 3 Analysis approaches for track geometry maintenance planning

\begin{tabular}{llc}
\hline Analysis approach & Description & Action and result \\
\hline Exception & $\begin{array}{c}\text { Manual/automatic analysis to } \\
\text { provide nature and location } \\
\text { of exception. }\end{array}$ & $\begin{array}{c}\text { Correct defect to reduce risk of accident } \\
\text { or damage to track or vehicles }\end{array}$ \\
$\begin{array}{c}\text { Track Condition } \\
\text { Assessment }\end{array}$ & $\begin{array}{c}\text { Analysis to provide numerical track } \\
\text { quality indices (TQI) for each } \\
\text { track segment }\end{array}$ & $\begin{array}{c}\text { Use in maintenance planning to guide deployment } \\
\text { of maintenance effort, thus reducing costs, } \\
\text { risk of emergency maintenance. }\end{array}$ \\
$\begin{array}{c}\text { Prediction of } \\
\text { Change in Track } \\
\text { Condition }\end{array}$ & $\begin{array}{c}\text { TQI change over time associated } \\
\text { with traffic, track structure and } \\
\text { maintenance data. }\end{array}$ & $\begin{array}{c}\text { Use to guide long-term maintenance planning, } \\
\text { understand causes of track degradation and } \\
\text { evaluation of maintenance effectiveness. }\end{array}$ \\
\hline
\end{tabular}

models have been developed to utilize this data more extensively, including use in maintenance planning, maintenance management, and maintenance decision making. This includes the ability to use more accurate data to predict the rate of degradation of the track and to determine when maintenance will be required.

\section{Analysis of Inspection Data}

\section{Analysis of Track Geometry Data}

Track geometry data represents the most commonly and widely used method of measuring track substructure (ballast and subgrade) condition and scheduling ballast related maintenance.

Table 4 Track quality indices used for different track geometry parameters

\begin{tabular}{ll}
\hline Track geometry parameter & Track quality index (TQI) \\
\hline Alignment & Standard deviation \\
Alignment & Standard deviation of short mid-chord offset (2 ft) \\
Profile & Standard deviation \\
Profile & Standard deviation of short mid-chord offset (2 ft) \\
Profile & Standard deviation of intermediate length mid-chord \\
& offset (16 ft) \\
Cross-level & Standard deviation \\
Cross-level & Standard deviation from balanced superelevation \\
Warp (20 ft) & Standard deviation \\
Warp (20 ft) & 99 percentile \\
Gage & Mean \\
Gage & Standard deviation \\
Gage & 99 percentile \\
Gage & Third moment of probability function (skewness) \\
Gage & Fourth moment of probability function (kurtosis) \\
&
\end{tabular}




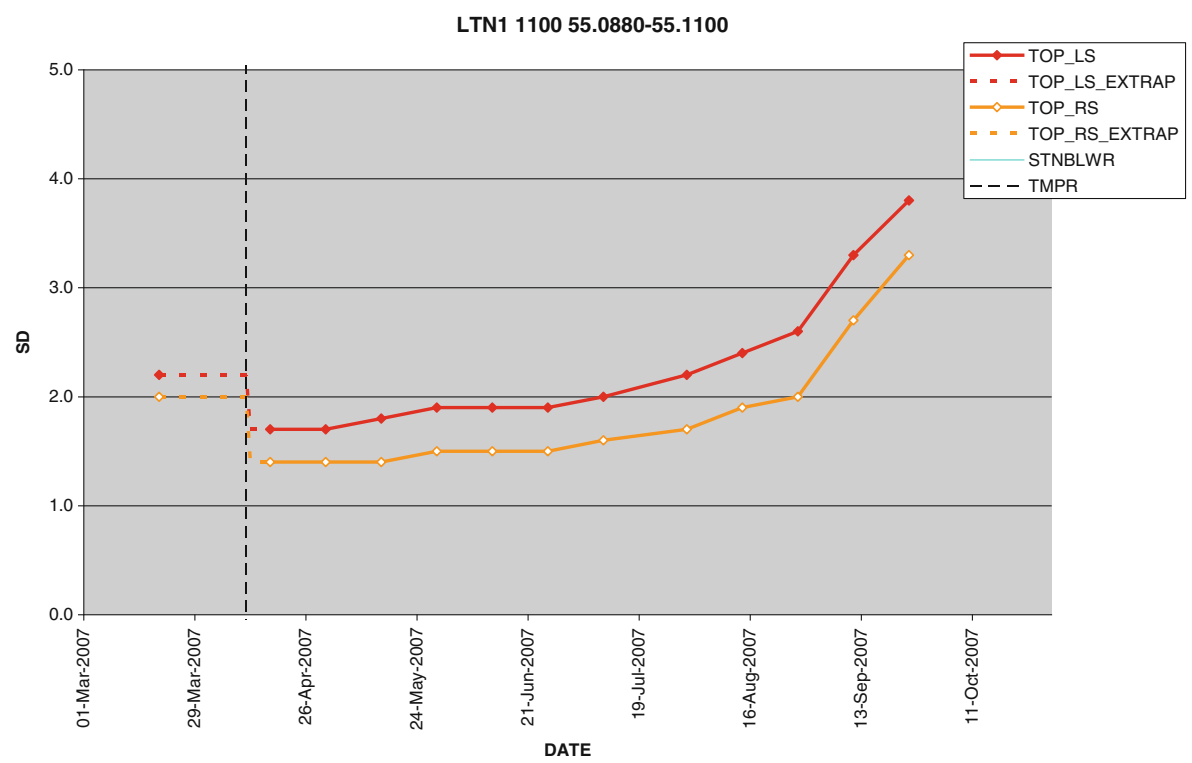

Fig. 11 Degradation of track after tamping [15]

Table 3 summarizes the three most commonly used approaches to the analysis of track geometry data.

The most commonly used approach is the exception approach which is incorporated in virtually every set of railway standards worldwide as well as in most government or

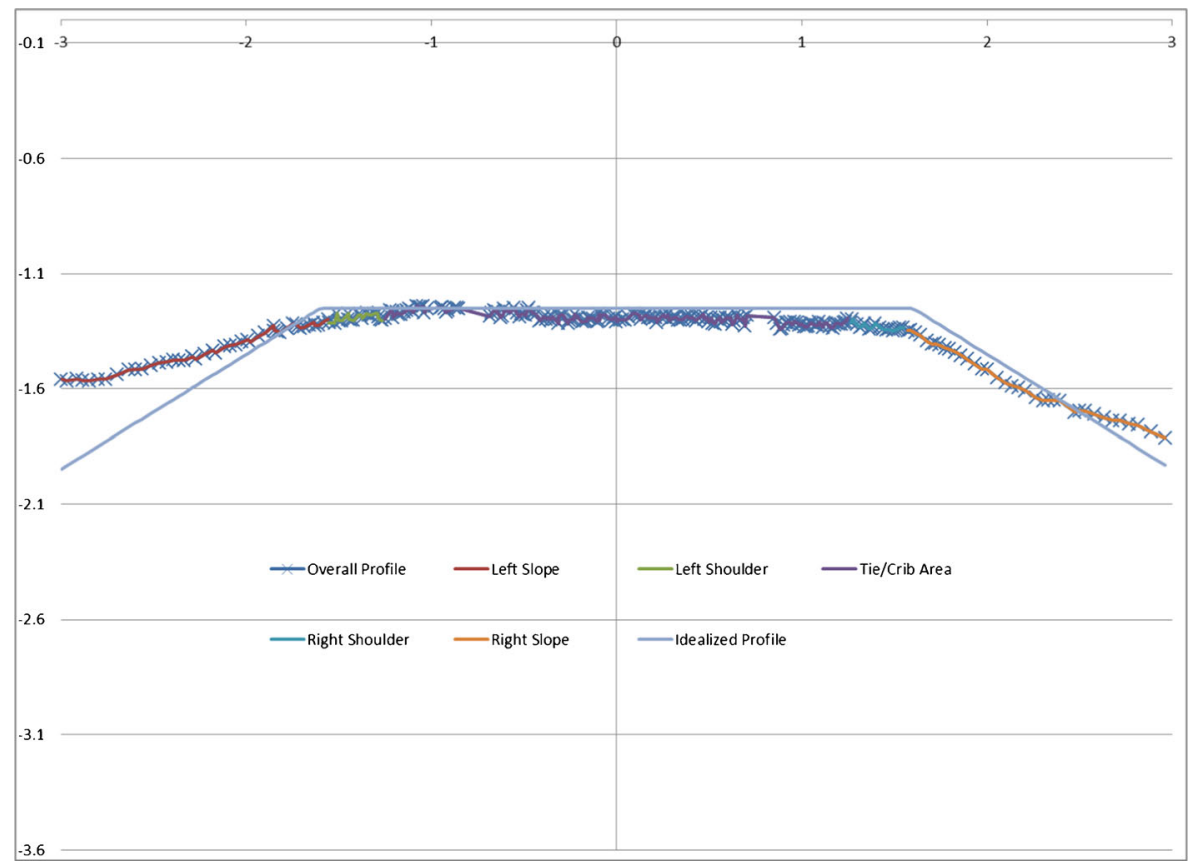

Fig. 12 Digitized LIDAR ballast profile with ideal profile overlay 


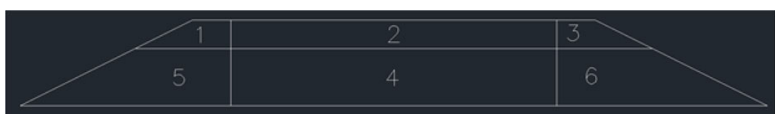

Fig. 13 Key ballast cross-section zones

regulatory standards, such as the Track Safety Standards of the US Federal Railroad Administration (FRA). Exception standards are based directly off of the track geometry data, as measured (analog or digital) directly from the track geometry (recording) car as illustrated in Fig. 2a. These are then compared against railroad or government standards and exceedances or "exceptions" are reported via a summary exception report as illustrated in Fig. 2 b.

In this approach, the rail-bound geometry car loads the track dynamically and measures deviations from railroad standards. These measurements, to include gage, profile, cross-level and alignment, are compared to regulatory limits. Generally, these limits are divided into:

- Red or safety limits which require immediate action

- Yellow or maintenance limits which require action in the short term

If either of these limits is exceeded, alerts are sent out to the local forces as well as to HQ. The data is also stored for future use. Maintenance, usually tamping of the ballast, is then scheduled to correct the reported exceptions.

While this exception-based approach provides for a basic level of safety, provided the inspection intervals are short enough to catch any rapid degradation of condition, it does not allow for any planning or evaluation of the degradation of the geometry with time.

The degradation of track surface (profile of one rail) at one point with time (traffic), as defined by the total deflection of the track at that point is nonlinear. However, geometry data is usually not taken with the frequency needed to get this detailed a degradation curve.

One approach to examining degradation of the geometry is to take multiple, sequential geometry measurements and overlay them to get an understanding of the rate of degradation. This is illustrated in Fig. 10, which presents three sequential crosslevel measurements, over a $300 \mathrm{~m}(1,000 \mathrm{ft})$ length of track [14]. The degradation behavior is clearly visible from this overlay.

However, while this is a useful approach for analysis of a specific problem area, it is virtually impossible to perform on an active basis for any large railway system. It requires analysis of every geometry channel at every location, and every measurement run.

In order to make this approach more manageable, railways have developed track quality indices or TQIs to provide a consolidation of the track geometry data to allow

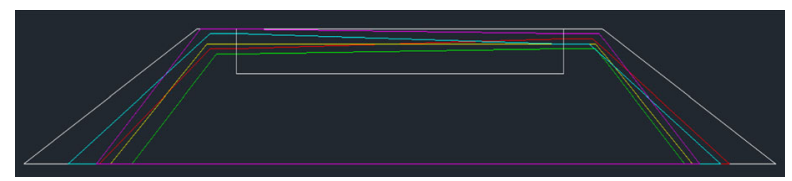

Fig. 14 Example overlay of multiple profiles 


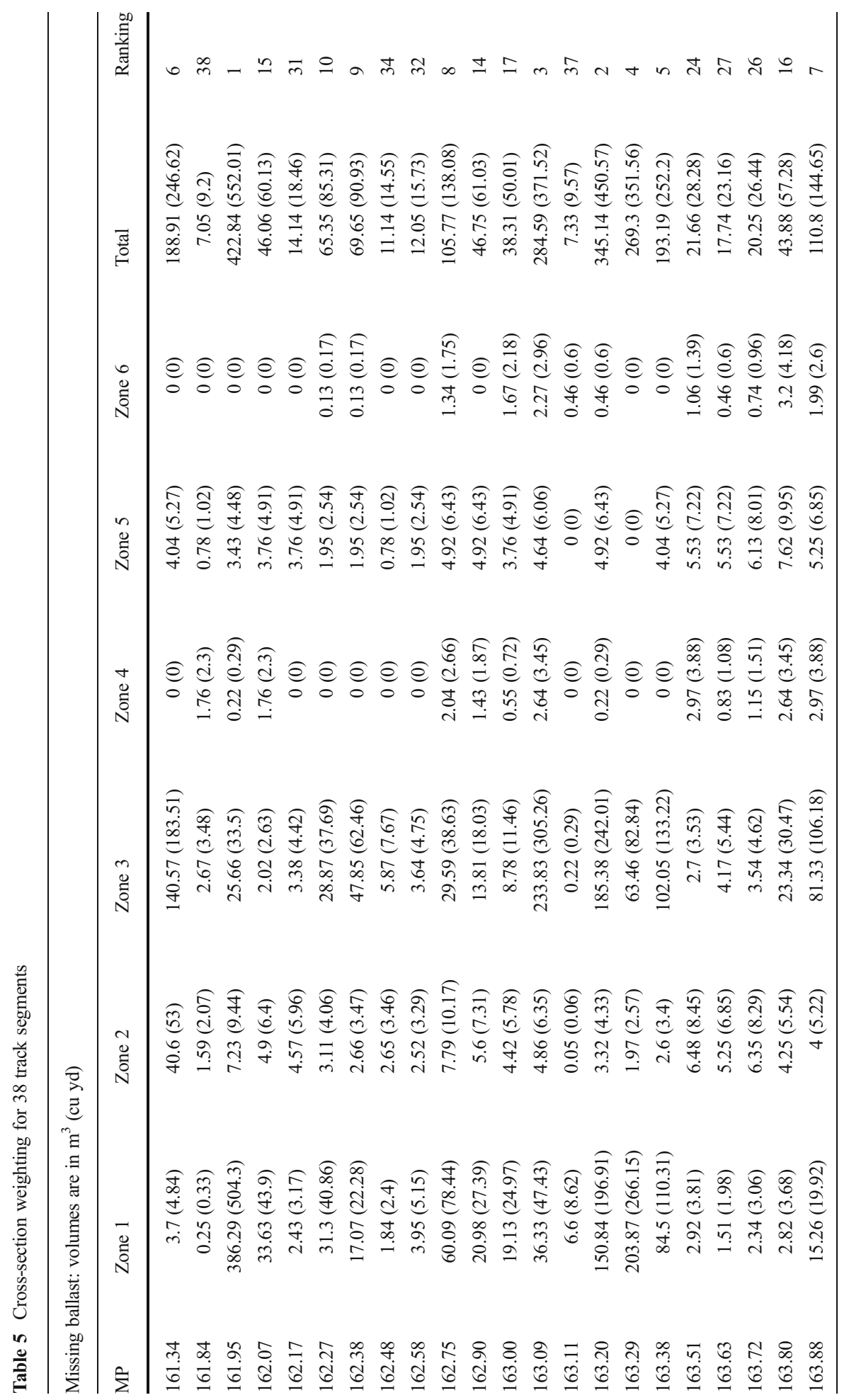




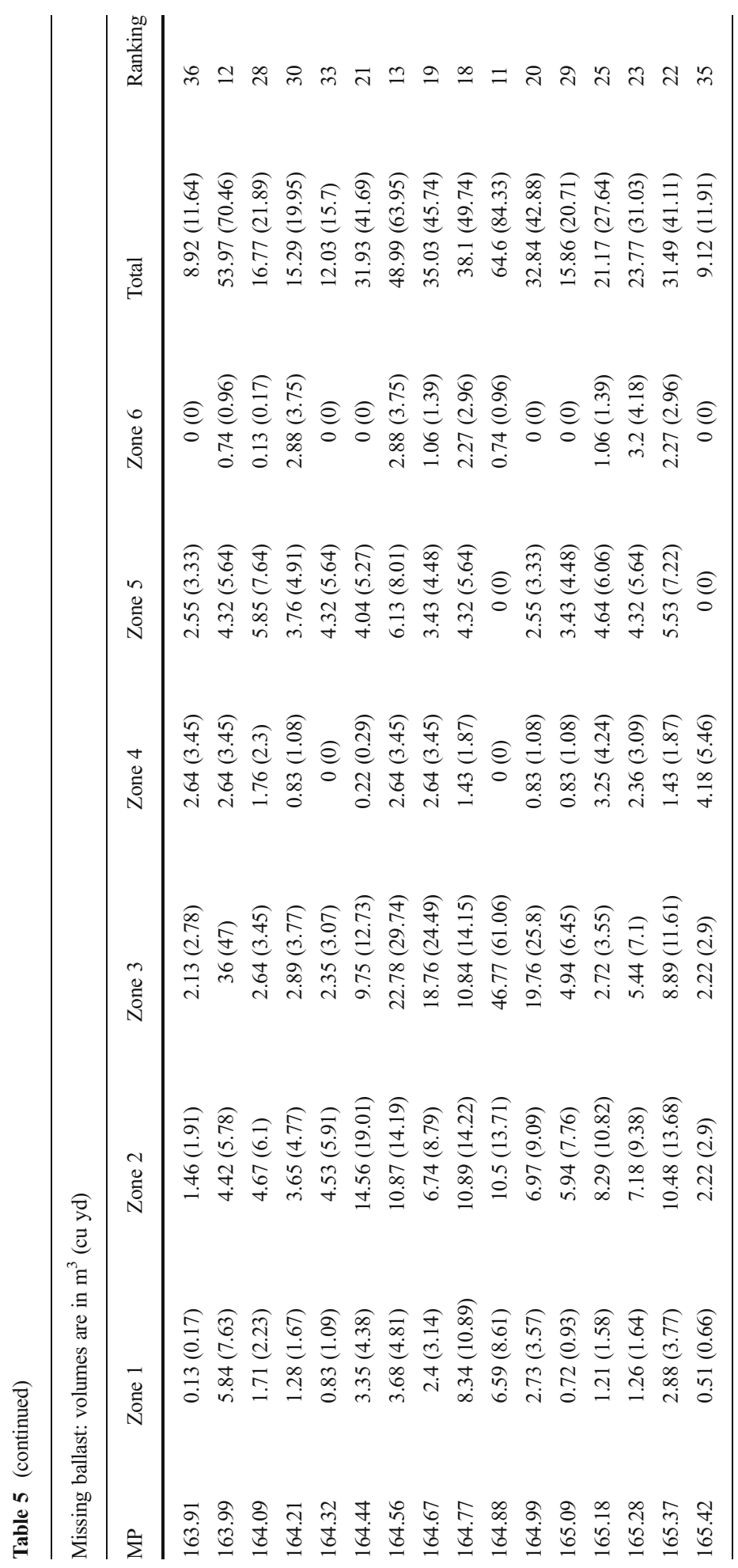


Fig. 15 Two vehicle test of combined GPR (lead vehicle) and LIDAR (trailing vehicle) inspection of ballast

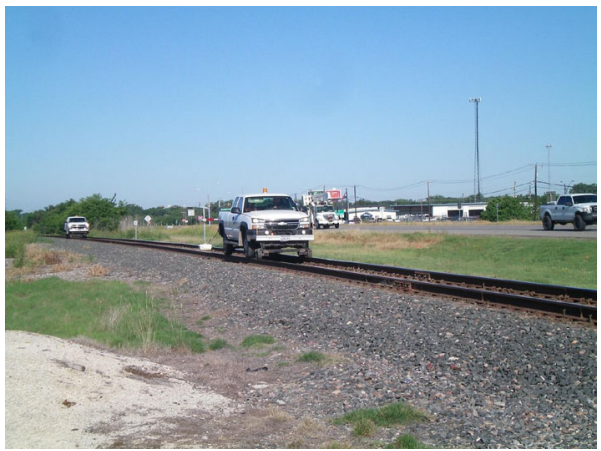

for more efficient analysis of track geometry degradation and long-term behavior. Because of the difference in behavior of different geometry parameters, various statistical or algebraic functions have been used to develop TQIs. This is illustrated in Table 4 which presents some commonly used TQIs as a function of the specific track geometry parameter. Thus, for example, the statistical standard deviation $(\sigma)$ is commonly used for such parameters as alignment, profile, and cross-level. Likewise, statistical mean is often used for gage.

Some railways also generate a combined TQI such that

$$
\mathrm{TQI}=\sum a_{i} \mathrm{TQI}_{i}
$$

Where

$\mathrm{TQI}_{i} \quad$ represents the summary statistic (TQI) for each of the individual geometry parameters $i$ (gage, left profile, right profile, cross-level, etc.)

$a_{i} \quad$ represents a weighting constant for each geometry parameter $i$

This TQI data can then be plotted with time or tonnage using sequential geometry car measurements, as illustrated in Fig. 11. This figure shows the standard deviation (TQI) of left and right surface (Top) for approximately $100 \mathrm{~m}$ of track with frequent track geometry measurements [15].

As can be seen from this figure, the TQI behavior is nonlinear. When the TQI approaches a defined threshold value, e.g., 4; then track surfacing is required. After surfacing is performed, the condition of the track (TQI) is improved such as illustrated in Fig. 11 in early April 2007 (TQI is reduced to approximately 1.5) and then proceeds to start the degradation process again. This type of degradation behavior allows for the forecasting of the rate of degradation and the planning of future track surfacing $[2,4]$.

\section{Analysis of LIDAR and GPR Ballast Depth Data}

The analysis of the LIDAR ballast profile output data is illustrated in Fig. 12 where digitized LIDAR data is overlaid onto an idealized track structure representing the top of tie, the shoulders, and the shoulder slope. The ideal ballast cross-section is defined by the user railroad and can differ from railroad to railroad as well as from track location to track location. For example, many railroads specify larger shoulders on 


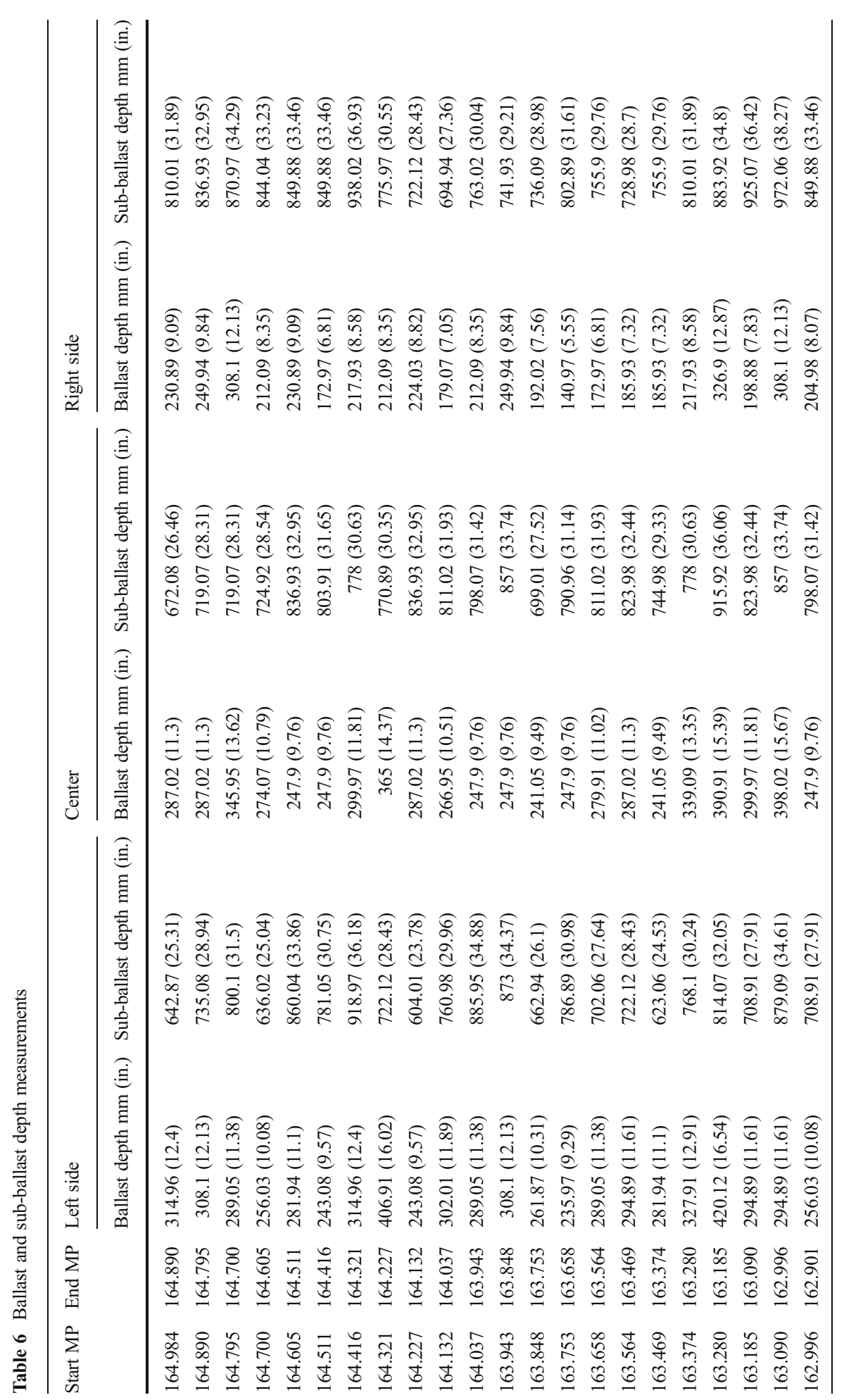




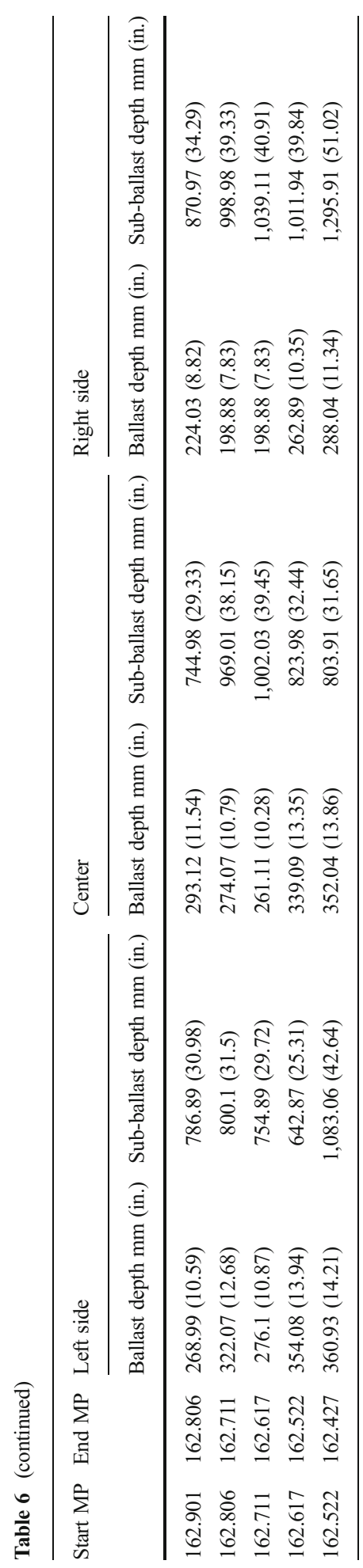




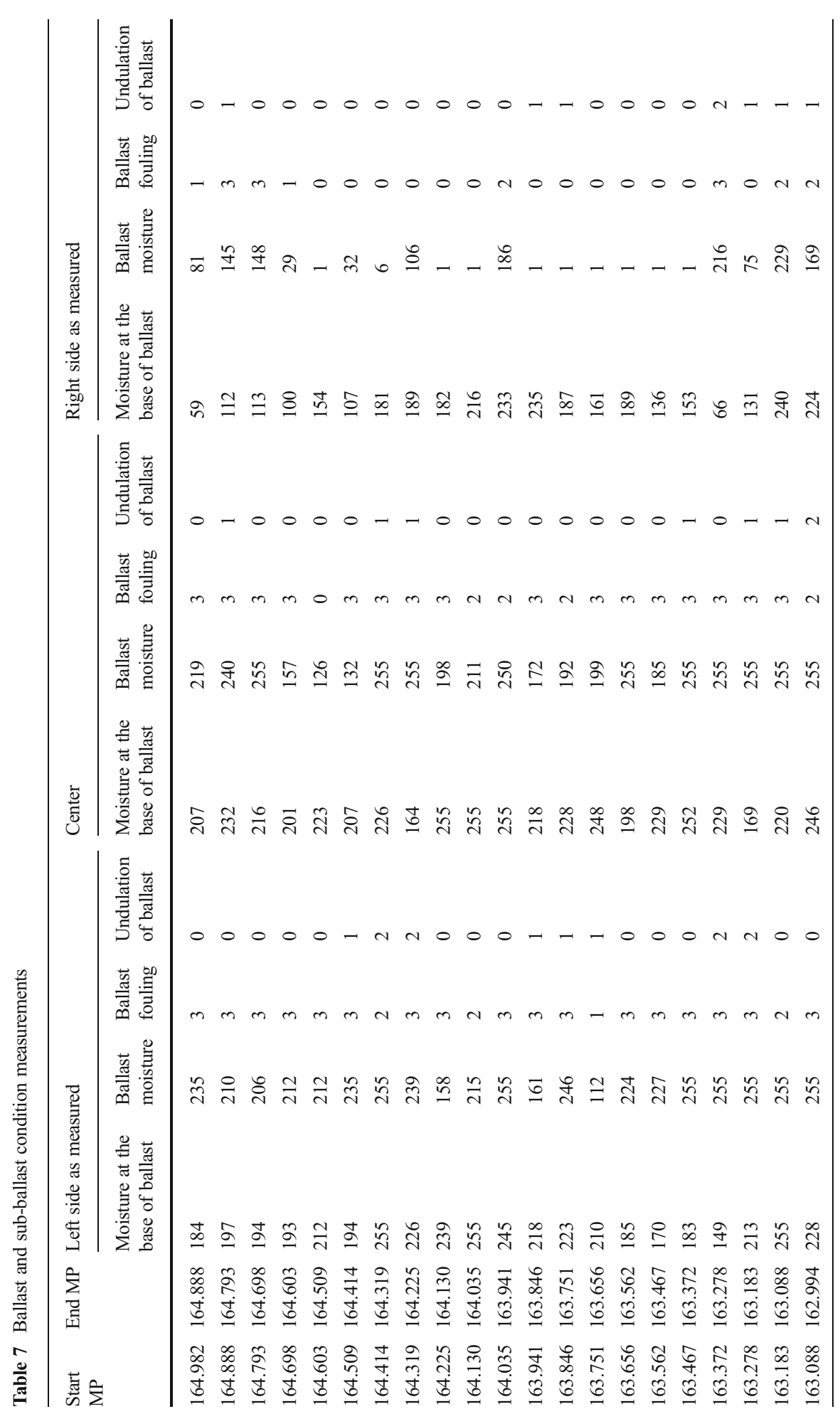




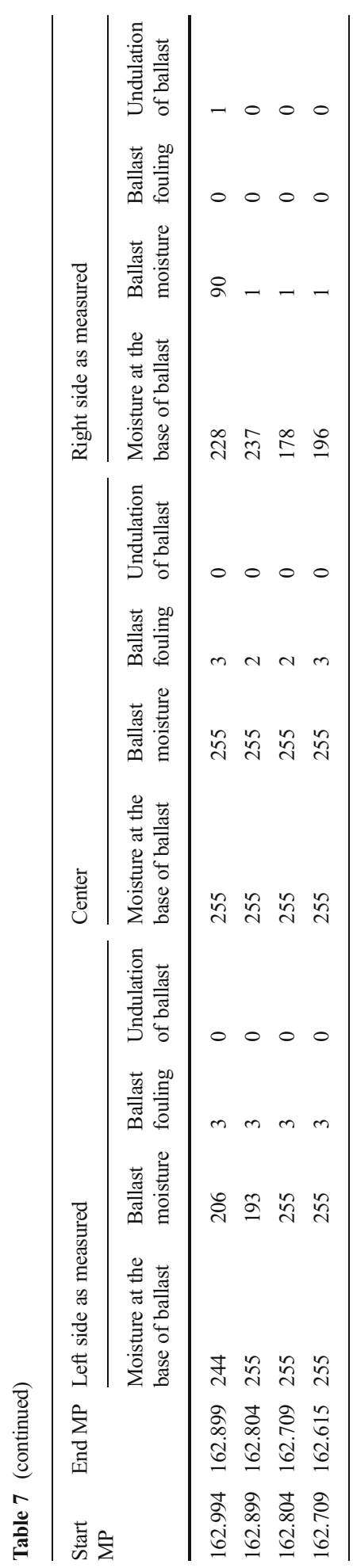


Table 8 Segment weighting for $401.6 \mathrm{~km}$ (1 mile) long segments

\begin{tabular}{|c|c|c|c|c|}
\hline Segment \# & $\begin{array}{l}\text { Unweighted volume } \\
\text { deficiency } \mathrm{m}^{3} \text { (cu yd) }\end{array}$ & $\begin{array}{l}\text { Weighted volume } \\
\text { deficiency } \mathrm{m}^{3} \text { (cu yd) }\end{array}$ & $\begin{array}{l}\text { Unweighted } \\
\text { prioritization rank }\end{array}$ & $\begin{array}{l}\text { Weighted } \\
\text { prioritization } \\
\text { rank }\end{array}$ \\
\hline 1 & $2,207.31(2,881.6)$ & $2,509.65(3,276.31)$ & 33 & 28 \\
\hline 2 & $2,417.42(3,155.9)$ & $2,745.21(3,583.83)$ & 27 & 22 \\
\hline 3 & $2,815.43(3,675.5)$ & $3,182.86(4,155.17)$ & 14 & 14 \\
\hline 4 & $4,424.6(5,776.24)$ & $5,180.17(6,762.62)$ & 3 & 2 \\
\hline 5 & $3,684.12(4,809.56)$ & $4,321.83(5,642.08)$ & 6 & 4 \\
\hline 6 & $2,791.7(3,644.52)$ & $3,296.63(4,303.7)$ & 18 & 13 \\
\hline 7 & $1,191.55(1,555.55)$ & $1,413.32(1,845.07)$ & 40 & 40 \\
\hline 8 & $1,596.88(2,084.7)$ & $1,896.86(2,476.32)$ & 39 & 38 \\
\hline 9 & $5,001.77(6,529.73)$ & $5,931.04(7,742.87)$ & 1 & 1 \\
\hline 10 & $2,408.7(3,144.52)$ & $2,877.14(3,756.06)$ & 28 & 17 \\
\hline 11 & $3,509.05(4,581.01)$ & $4,198.82(5,481.49)$ & 7 & 5 \\
\hline 12 & $2,793.21(3,646.49)$ & $3,340.92(4,361.51)$ & 17 & 10 \\
\hline 13 & $3,240.35(4,230.22)$ & $3,858.4(5,037.08)$ & 8 & 7 \\
\hline 14 & $2,225.15(2,904.9)$ & $2,455.19(3,205.21)$ & 31 & 29 \\
\hline 15 & $2,544.83(3,322.23)$ & $2,823.32(3,685.79)$ & 24 & 19 \\
\hline 16 & $1,852.95(2,418.99)$ & $2,054.04(2,681.52)$ & 37 & 36 \\
\hline 17 & $2,942.16(3,840.94)$ & $3,299.12(4,306.95)$ & 12 & 12 \\
\hline 18 & $3,072.75(4,011.42)$ & $3,440.01(4,490.88)$ & 9 & 9 \\
\hline 19 & $2,600.62(3,395.07)$ & $2,916.7(3,807.7)$ & 23 & 16 \\
\hline 20 & $2,971.53(3,879.28)$ & $3,313.56(4,325.8)$ & 11 & 11 \\
\hline 21 & $2,622.92(3,424.18)$ & $2,622.92(3,424.18)$ & 22 & 26 \\
\hline 22 & $2,194.01(2,864.24)$ & $2,194.01(2,864.24)$ & 34 & 34 \\
\hline 23 & $2,808.72(3,666.73)$ & $2,808.72(3,666.73)$ & 16 & 21 \\
\hline 24 & $3,039.16(3,967.57)$ & $3,039.16(3,967.57)$ & 10 & 15 \\
\hline 25 & $3,797.26(4,957.26)$ & $3,797.26(4,957.26)$ & 5 & 8 \\
\hline 26 & $2,810.84(3,669.51)$ & $2,810.84(3,669.51)$ & 15 & 20 \\
\hline 27 & $2,423.08(3,163.29)$ & $2,423.08(3,163.29)$ & 26 & 30 \\
\hline 28 & $2,271.03(2,964.79)$ & $2,271.03(2,964.79)$ & 30 & 32 \\
\hline 29 & $2,135.42(2,787.76)$ & $2,135.42(2,787.76)$ & 35 & 35 \\
\hline 30 & $2,663.88(3,477.65)$ & $2,663.88(3,477.65)$ & 20 & 24 \\
\hline 31 & $2,835(3,701.05)$ & $2,835(3,701.05)$ & 13 & 18 \\
\hline 32 & $2,637.18(3,442.8)$ & $2,637.18(3,442.8)$ & 21 & 25 \\
\hline 33 & $2,212.08(2,887.83)$ & $2,212.08(2,887.83)$ & 32 & 33 \\
\hline 34 & $1,900.68(2,481.31)$ & $1,900.68(2,481.31)$ & 36 & 37 \\
\hline 35 & $2,529.24(3,301.88)$ & $2,529.24(3,301.88)$ & 25 & 27 \\
\hline 36 & $1,639.95(2,140.93)$ & $1,639.95(2,140.93)$ & 38 & 39 \\
\hline 37 & $4,442.62(5,799.76)$ & $4,442.62(5,799.76)$ & 2 & 3 \\
\hline 38 & $4,129.84(5,391.43)$ & $4,129.84(5,391.43)$ & 4 & 6 \\
\hline 39 & $2,712.17(3,540.69)$ & $2,712.17(3,540.69)$ & 19 & 23 \\
\hline 40 & $2,275.72(2,970.91)$ & $2,275.72(2,970.91)$ & 29 & 31 \\
\hline
\end{tabular}


curves than on tangent track; for example $457 \mathrm{~mm}\left(18^{\prime \prime}\right)$ shoulders on sharp curves vs. $305 \mathrm{~mm}\left(12^{\prime \prime}\right)$ on tangent. Likewise, continuously welded rail (CWR) track will have a larger shoulder than jointed track, e.g., 305 vs. $152 \mathrm{~mm}$ (12" vs. 6") [1]. The calculation of the missing profile ballast can then be performed (Fig. 12).

Calculation of missing ballast below the bottom of the tie is likewise performed using an overlay of the GPR measured bottom of the ballast (top of subgrade) and the railroad defined idealized ballast depth (which again can vary as a function of location, particularly for areas of poor or weak subgrade material).

In order to facilitate the calculation of the missing ballast, six ballast zones are defined for any given cross-section of the ballast as follows (see Fig. 13):
1. Left shoulder
2. Ballast crib
3. Right shoulder
4. Ballast under bottom of tie
5. Ballast under left shoulder
6. Ballast under right shoulder

Note that the cross-section at a cross-tie will differ from the cross-section between ties, in that zone 2, the crib zone, will have ballast between the ties but will be filled by the cross-tie itself at the tie location. This must be properly accounted for when calculating ballast volumes along the track.

Thus, for each of the six zones, the difference between the idealized ballast section (as defined by the railroad for that track location) and the actual ballast section (as measured from the LIDAR-based profile and GPR-based depth of ballast) is calculated and then summed to get the missing ballast area for the defined cross-section.

Noting the inspection interval of the LIDAR unit along the track (which ranges from approximately $9 \mathrm{~mm}\left[0.35^{\prime \prime}\right]$ at $1.6 \mathrm{kph}$ [1 $\left.\mathrm{mph}\right]$ to $178 \mathrm{~mm}$ [7"] at $32 \mathrm{kph}[20 \mathrm{mph}]$ ), the volume of missing ballast can be calculated by multiplying the ballast missing from each cross-section by the longitudinal inspection interval, and then summing up these volumes for the desired length of track (e.g., mile intervals). Note the missing ballast volume must be adjusted to reflect the presence of the cross-ties at their actual spacing (nominally $228 \mathrm{~mm}$ [9 in.] wide every $495 \mathrm{~mm}$ [19.5 in.]).

The calculation of the missing profile ballast can be visualized in Fig. 12, where the missing ballast is clearly seen as the gap between the idealized (desired) profile and the actual profile. Thus, noting Fig. 12, it can be seen that the left shoulder is missing ballast at the top of the shoulder, but further down the slope, the actual ballast profile extends beyond the idealized profile, indicating a surplus of ballast in this area. ${ }^{2}$ On the right side, the gap is more pronounced and extends down the shoulder slope. In the crib, there is a nonuniform ballast section, with significantly more missing ballast on the right side of the crib.

Calculation of missing ballast below the bottom of the tie is likewise performed using an overlay of the GPR measured bottom of the ballast (top of subgrade) and the

\footnotetext{
${ }^{2}$ Surplus ballast, i.e., ballast that is outside the idealized profile boundary is not included in the missing ballast calculation.
} 
Table 9 Segment weighting for 8 five-mile long segments

\begin{tabular}{lllll}
\hline $\begin{array}{l}\text { Consolidated } \\
\text { segment \# }\end{array}$ & $\begin{array}{l}\text { Unweighted volume } \\
\text { deficiency } \mathrm{m}^{3}(\mathrm{cu} y \mathrm{~d})\end{array}$ & $\begin{array}{l}\text { Weighted volume } \\
\text { deficiency } \mathrm{m}^{3}(\mathrm{cu} y \mathrm{y})\end{array}$ & $\begin{array}{l}\text { Unweighted } \\
\text { prioritization } \\
\text { rank }\end{array}$ & $\begin{array}{l}\text { Weighted } \\
\text { prioritization } \\
\text { rank }\end{array}$ \\
\hline $1-5$ & $15,549.03(20,299)$ & $17,939.72(23,420)$ & 1 & 1 \\
$6-10$ & $12,990.59(16,959)$ & $15,414.98(20,124)$ & 6 & 3 \\
$11-15$ & $14,312.71(18,685)$ & $16,676.59(21,771)$ & 4 & 2 \\
$16-20$ & $13,440.24(17,546)$ & $15,023.56(19,613)$ & 5 & 5 \\
$21-25$ & $14,462.08(18,880)$ & $14,462.08(18,880)$ & 3 & 6 \\
$26-30$ & $12,304.26(16,063)$ & $12,304.26(16,063)$ & 7 & 7 \\
$31-35$ & $12,114.29(15,815)$ & $12,114.29(15,815)$ & 8 & 8 \\
$36-40$ & $15,200.5(19,844)$ & $15,200.5(19,844)$ & 2 & 4 \\
\hline
\end{tabular}

railroad defined idealized ballast depth (which again can vary as a function of location, particularly for areas of poor or weak subgrade material).

Figure 14 shows overlays of several different simplified ballast cross-sections and illustrates how the missing ballast area will vary as a function of the actual profile.

The corresponding missing ballast volumes for each of these profiles, prioritized by missing volume are as follows:

Ranking of sections based on volume deficiency per length of track
1. Section 3 Green: $0.925 \mathrm{~m}^{3} / \mathrm{m}(0.37 \mathrm{CY} / \mathrm{FT})$
2. Section 2 Yellow: $0.725 \mathrm{~m}^{3} / \mathrm{m}(0.29 \mathrm{CY} / \mathrm{FT})$
3. Section 1 Red: $0.625 \mathrm{~m}^{3} / \mathrm{m}(0.25 \mathrm{CY} / \mathrm{FT})$
4. Section 4 Cyan: $0.500 \mathrm{~m}^{3} / \mathrm{m}(0.20 \mathrm{CY} / \mathrm{FT})$
5. Section 5 Magenta: $0.450 \mathrm{~m}^{3} / \mathrm{m}(0.18 \mathrm{CY} / \mathrm{FT})$

Table 5 presents the results of a missing ballast analysis for 38 segments of actual track data from a major US Class 1 railroad. Each segment is approximately $150 \mathrm{~m}$ ( 0.1 miles or $500 \mathrm{ft}$ ) in length. These results were from a combined GPR and LIDAR test as shown in Fig. 15. Table 5 shows the missing ballast in each of the six zones defined previously, to include left and right shoulder (zones 1 and 3), crib (zone 2), and ballast under the tie (zone 4) and shoulders (zone 5 and 6). It should be noted that the missing ballast for zones 1, 2, and 3 were obtained from the LIDAR measurements and the missing ballast for zones 4, 5, and 6 were obtained from the GPR measurements. The total missing ballast and the prioritization of these 38 segments are also presented in Table 5. Tables 6 and 7 present the results of the GPR measurement of ballast/subballast depth and ballast condition, respectively.

Table 8 presents the results of a missing ballast analysis for 40 segments of track data, each approximately $1.6 \mathrm{~km}(1 \mathrm{mile})$ in length for a total of approximately $64 \mathrm{~km}$ (40 miles). In addition to the missing ballast calculation, a "weighted" missing ballast calculation is also presented based on a missing ballast prioritization methodology developed to assist in ballast replacement decisions [12]. Table 8 presents and compares 
the unadjusted (unweighted) volume of missing ballast and the weighted volume of missing ballast together with their relative prioritization.

To more realistically compare the way railroads actually add ballast, these $401.6 \mathrm{~km}$ (1 mile) segments were in turn consolidated into 8-km (5-mile) segments as shown in Table 9. Here too, the significant effect of the analysis can be seen.

\section{Conclusion}

Maintenance of a proper ballast section, to include ballast cross-section (profile) and depth is of critical importance to railroads from both a safety and ongoing maintenance point of view. Inadequate ballast sections can result in rapid loss of track geometry (alignment, profile, cross-level, twist or warp, etc.) as well as potential catastrophic failure such as track buckling, which is directly assisted with inadequate ballast resistance.

A new generation of nondestructive inspection technologies such as the LIDARbased ballast saver inspection system for profile measurement and GPR for ballast depth measurement provide good information about ballast profile and depth and can be used to determine the amount of missing ballast as well as the condition of the ballast itself. This includes determination of where and how much ballast should be placed, such as ballast at end of ties (shoulders), under ties, and in cribs. Used together, they can provide significant additional information about the condition of the ballast and the steps needed to bring this condition up to standard.

These ballast (and subgrade) condition measurement techniques supplement and complement the traditional track geometry car measurements which provide information about ballast (and subgrade) condition only indirectly. This in turn allows for better decision making on track substructure maintenance to include options for cleaning or replacing the ballast, improving drainage, or simply adding ballast to increase the depth of the ballast layer.

This further allows track maintenance engineers to identify and correct the root cause of track degradation problems, rather than just simply correcting the symptoms, as they appear, by tamping and related track geometry corrective actions.

Acknowledgments The authors would like to acknowledge John Cronin, Graduate Student at the University of Delaware for his assistance in performing the analysis of the missing and weighted ballast sections. The authors would also like to acknowledge IDS Ingegneria Dei Sistemi SpA (Italy) for its support of the combined LIDAR and GPR tests discussed in this paper.

\section{References}

1. American Railway Engineering and Maintenance of Way Association: [AREMA] "Manual for Railway Engineering" (2012)

2. Bonaventura, C.S., Zarembski, A.M., Palese, J.W.: Determination of optimum intervention time for track surfacing based on economic minimization of maintenance costs. IHHA, Calgary (2011)

3. Dogneton, P.: Axial and lateral track ballast resistance", railroad track mechanics and technology. Pergamon, New York (1978)

4. Ebrahimi, A., Keene, A.: Mechanistic maintenance planning of railway ballast AREMA Sept 2011. AREMA, Minneapolis (2011) 
5. Hay, W.W.: Railroad engineering. Wiley, New York (1982)

6. Kish, A.: On the Fundamentals of Track Lateral Resistance, American Railway Engineering and Maintenance of Way Association. (2011)

7. Lichtberger, R.: Track compendium. Eurail, Hamburg (2011)

8. Norman, C.: Measurement of Track Modulus from a Moving Railcar, Master's thesis, University of Nebraska, May, 2004. (2004)

9. Samavedan, G.,et al.: "Track Resistance Characterization and Correlation Study", FRA Report DOT/ FRA/ORD-94/07, January 1995. (1995)

10. Selig, E.T., Waters, J.M.: Track geotechnology and substructure management. Telford, London (1994)

11. Talbot, A.N., et al.: "Stresses in Railroad Track-The Talbot Reports", American Railway Engineering Association. (1980)

12. Zarembski, A.M.: "Implementation of a Track Substructure Support System to Address Track Supports Problems on Amtrak's' High Speed Northeast Corridor” Transportation Research Board Annual Meeting, January 2013. (2013)

13. Zarembski, A.M., Choros, J.: "On the Measurement and Calculation of Vertical Track Modulus", Bulletin of the American Railway Engineering Association, Bulletin 675, Volume 81, November-December 1979. (1979)

14. Zarembski, A.M., Grissom, G.T., Euston, T.L.: "Use of Ballast Inspection Technology for the Prioritization, Planning and Management of Ballast Delivery and Placement" American Railway Engineering Association Annual Conference, Indianapolis, IN, September 2013. (2013)

15. Zarembski, A.M., Newman, G.R. (2008), "Comparative Technical and Economic Analysis of Stoneblowing vs. Tamping”, AREMA 2008 Annual Conference and Exposition, Salt Lake City, UT, September 2008 